\title{
Crowdsourcing of weather observations at national meteorological and hydrological services in Europe
}

\author{
Thomas Krennert, Georg Pistotnik, Rainer Kaltenberger, and Christian Csekits \\ ZAMG, Zentralanstalt für Meteorologie und Geodynamik, Hohe Warte 38, 1190 Vienna, Austria \\ Correspondence: Thomas Krennert (t.krennert@zamg.ac.at)
}

Received: 12 February 2018 - Accepted: 27 March 2018 - Published: 18 May 2018

\begin{abstract}
National Meteorological and Hydrological Services (NMHSs) increase their efforts to deliver impactbased weather forecasts and warnings. At the same time, a desired increase in cost-efficiency prompts these services to automatize their weather station networks and to reduce the number of human observers, which leads to a lack of "ground truth" information about weather phenomena and their impact. A possible alternative is to encourage the general public to submit weather observations, which may include crucial information especially in high-impact situations.

We wish to provide an overview of the state and properties of existing collaborations between NMHSs and voluntary weather observers or storm spotters across Europe. For that purpose, we performed a survey among 30 European NMHSs, from which 22 NMHSs returned our questionnaire. This study summarizes the most important findings and evaluates the use of "crowdsourced" information. $86 \%$ of the surveyed NMHSs utilize information provided by the general public, $50 \%$ have established official collaborations with spotter groups, and $18 \%$ have formalized them. The observations are most commonly used for a real-time improvement of severe weather warnings, their verification, and an establishment of a climatology of severe weather events.

The importance of these volunteered weather and impact observations has strongly risen over the past decade. We expect that this trend will continue and that storm spotters will become an essential part in severe weather warning, like they have been for decades in the United States of America. A rising number of incoming reports implies that quality management will become an increasing issue, and we finally discuss an idea how to handle this challenge.
\end{abstract}

\section{Introduction}

Operational human weather observers are becoming increasingly rare among National Meteorological and Hydrological Services (NMHSs) across Europe. Networks of automated weather stations provide point wise "snapshots" of meteorological properties, but are naturally limited in their ability to reflect their spatial distribution. Neither can they give any hints about the impact and possible damages of (localized) severe weather events. Alternative ways of ground truth information therefore become more and more important for NMHSs, especially when considering a rising demand for impact-related forecasts and warnings.

The process of encouraging the public to participate in scientific research is a new and rapidly evolving field. It is often termed "Citizen Science" (Bonney et al., 2009; Eitzel et al.,
2017), though alternative notions like "Public Participation in Scientific Research" exist as well (Shirk et al., 2012). The range of participatory approaches may be manifold, but an inclusion of members of the public to achieve a broadened participation in science is central and overarching (Eitzel et al., 2017). One such approach is "Crowdsourcing", which describes "an open call to a wide group to aid in some kind of labour" (Eitzel et al., 2017). The internet is almost always the medium to reach a large group with such an open call, and hence constitutes the technological basis upon which crowdsourcing is operated (Estellés-Arolas and González-Ladrónde-Guevara, 2012). The tasks assigned to the "crowd" are not necessarily scientific ones, but the potential benefit of their contributions to scientific problems is evident. A synthesis of various vague or fragmentary former paraphrases 
of the still nascent approach of crowdsourcing into a comprehensive definition was performed by Estellés-Arolas and González-Ladrón-de-Guevara (2012).

It seems to be a logical step to utilize the Crowdsourcing concept for a matter as omnipresent as the weather. There are manifold reasons why people could have a particular interest in weather. It may be because their profession strongly relies on weather conditions (e.g., farmers, construction workers, vehicle drivers, or any other kind of field workers); it may be for recreational reasons (e.g., mountaineers or other outdoor sportsmen and - women); finally, some people exhibit a special interest in the subject of meteorology itself, though they did not turn it into their profession. These people all have in common that they observe the weather closely and frequently, and that their observations can turn out very valuable especially in high-impact weather situations. The rising participatory character of the internet ("web 2.0") made it easier for these enthusiasts to connect, to exchange information and to organize themselves in various ways from low levels (e.g., a discussion forum or a common social media platform) to high levels (e.g., the foundation of a non-profit association with clearly defined goals).

Some of these people, though not necessarily so, have an enhanced interest in high-impact weather situations. They are then not plain weather observers anymore, but rather act as storm spotters (i.e., they increase their observation intensity in "interesting" situations) or even storm chasers (i.e., they are willing to drive somewhere to experience the most "exciting" weather phenomena). These two terms are most frequently used in a context of convective severe weather, and their information adds most value in these situations due to the special volatility inherent to thunderstorms. However, an individual storm spotter or chaser may have a particular interest in any other weather phenomenon as well. For example, he/she may want to drive to a hilltop to experience (or even measure) the highest wind gusts during a wintertime windstorm, or go to the expected epicentre of a heavy snowfall event to see the most snow on the ground.

The prototype of an inclusion of these weather enthusiasts into the forecasting and warning process is the organization of storm spotters and chasers into the "Skywarn" association in the United States of America and their collaboration with the US National Weather Service, which started early in the 1950s. Real-time observations of severe weather and its impact by these voluntary observers play a crucial role especially in the process of tornado warnings, and will likely ever continue to do so despite the refinements in radar technology (Doswell III et al., 1999). This collaboration between the National Weather Service and Skywarn has acted as a blueprint for similar activities in Europe, though there may be variations and particularities across different countries.

European NMHSs have started to acknowledge these people and the information they provide, and collaborations between NMHSs and voluntary weather observers have become more frequent during the last few years. Though
Rauhala and Schultz (2009) pointed out that information from voluntary storm spotters was already incorporated into the severe weather warning process by a few European NMHSs a decade ago, no updated and comprehensive overview about such collaborations is available yet. In order to fill this gap, we carried out a survey in form of a questionnaire which was sent to the heads of the weather and forecasting departments of 30 European NMHSs, including Israel, Turkey and Cyprus. We received 22 responses. We will summarize the most important results in Sect. 2 of this paper and provide a discussion in Sect. 3.

\section{Results}

The questions of our survey can be grouped into three theme blocks and are listed below.

1. A: crowdsourcing and collaborations between NMHSs and spotter groups:

- A.1: do you ask for volunteered information by the public, spotters or spotter groups?

- A.2: do you collaborate with spotter groups?

- A.3: is this collaboration formalized?

2. B: quality management and archiving of reports:

- B.1: do you give advice, offer education or training for spotters?

- B.2: do you perform a quality control of incoming reports?

- B.3: is it possible to include photo or video material into reports?

- B.4: do you archive reports?

- B.5: do you input reports into the European Severe Weather Database (ESWD)?

3. C: collection and usage of information:

- C.1: do you collect information about severe weather events only, or also about non-severe weather events?

- C.2: how is the information collected?

- C.3: how do you use these data?

Figure 1 provides a graphic overview of the answers to the questions of theme blocks (A) and (B), which mostly needed a simple "yes" or "no". In addition, they offered an option to provide specifications or further information. Theme block (C) required less formalized answers which were more difficult to categorize. In all cases, we have to emphasize that we used the information as provided, unless in (rare) cases of obvious contradictions. We therefore cannot rule out that individual pieces of information might be incomplete or 


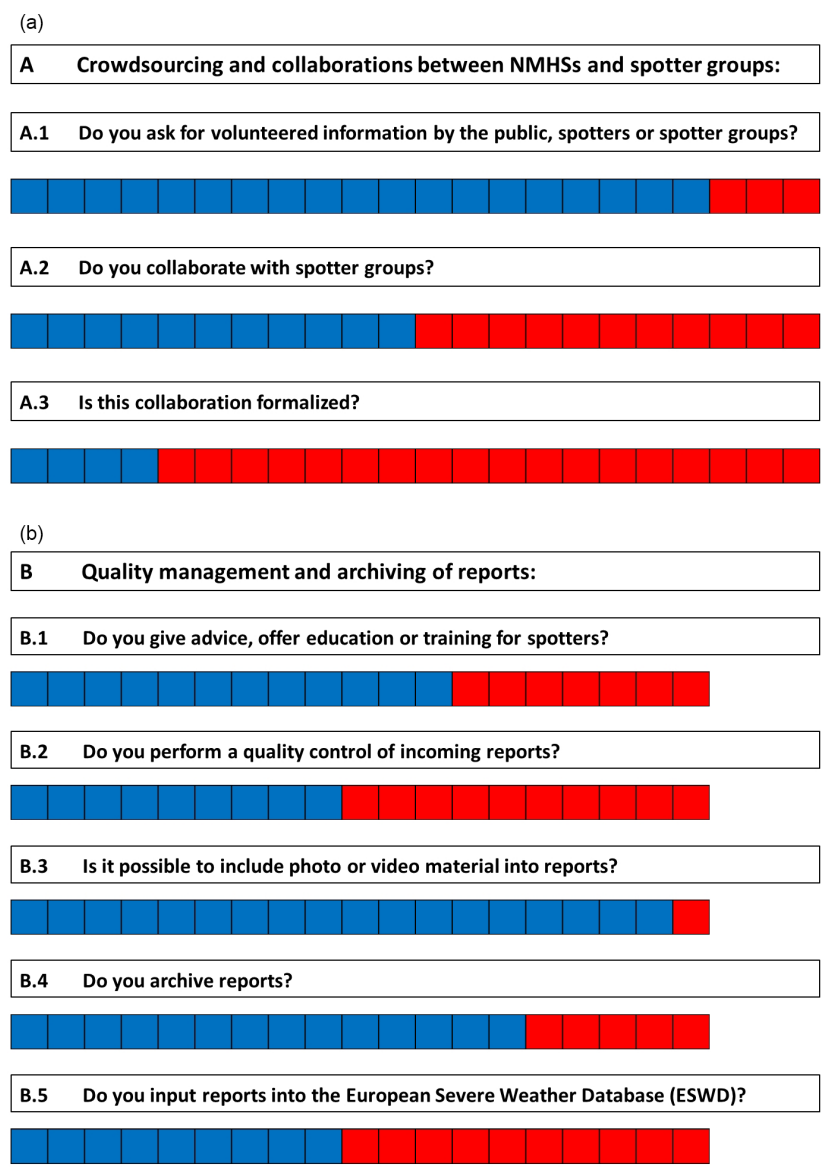

Figure 1. Graphic overview of replies to the questions of theme blocks (a) and (b) collected from the 22 surveyed NMHSs. Blue means "yes", red means "no". Note that the entirety was reduced from 22 to 19 for the questions of theme block (b), as three NMHSs do not perform active crowdsourcing.

wrong. In particular, not all existing spotter groups may be known to the responsible people filling out our questionnaire, which means that their true numbers may be even higher and our estimates are quite conservative.

\subsection{Crowdsourcing and collaborations between NMHSs and spotter groups}

Nineteen of the 22 surveyed NMHSs ( $86 \%$ ) actively conduct crowdsourcing in terms that citizens and spotters are encouraged to report weather- and damage-related observations on a voluntary basis (Question A.1). In the remaining three countries, the NMHSs do not actively ask the general public or spotters for observations, but some of their forecasters and scientists may individually gather openly available information via different sources, e.g. social media platforms. Eleven of the surveyed NMHSs (50\%) have official collaborations with spotter groups or similar associations (Question A.2), four of which are formalized (37\% of collaborating or $18 \%$ of the entirety of NMHSs; Question A.3). Most of these formalizations are realized with a Memorandum of Understanding, written agreements or contracts which contain rights and obligations of both sides and regulate the exchange of data and information as well as their respective usage. An overview of answers by country to theme block (A) is provided in Fig. 2.

It is an interesting detail that 15 of the 22 surveyed NMHSs (64\%) are aware of more than one national spotter group or weather-related association. This partitioning may be due to these organizations' focus on particular regions or specific weather events, or in some cases due to internal disputes between spotters which resulted in a state of rivalry with potentially unfavourable consequences for the entire system's functionality (Doswell III et al., 1999). Five NMHSs (45\% of collaborating or $23 \%$ of the entirety of NMHSs) maintain collaborations with more than one spotter group or similar partner organization.

\subsection{Quality management and archiving of reports}

The questions of theme block (B) could only be answered by those NMHSs who are engaged in active crowdsourcing. This means that the entirety of our sample is henceforth reduced from 22 to 19.

Twelve NMHSs (63\%)give various advices to laypersons for education and training (Question B.1). These advices include individual training, training courses or workshops, online tutorials or manuals, or similar training material or procedures. Some of these activities are also combined with exams or tests.

Nine of these 19 NMHSs (47\%) apply a quality control to incoming reports (Question B.2), typically in form of a plausibility check by professional staff with other meteorological data. All but one (95\%) allow an inclusion of photo or video material into reports (Question B.3), which naturally facilitates a manual quality checking procedure.

Fourteen of these 19 NMHSs (74\%) archive incoming data (Question B.4). Nine of them (47\%) exchange data with the European Severe Weather Database (ESWD) run by the European Severe Storms Laboratory (Question B.5).

Figure 3 provides an overview of the replies by country to Questions B.1, B.2, and B.4.

\subsection{Collection and usage of information}

Seven of 19 NMHSs (32\%) are mainly interested in severe weather events (Question C.1). The rest receives information about any weather states, but in some countries their totality is divided to discriminate between severe and non-severe events: in total, twelve of 19 NMHSs (63\%) mentioned quantitative thresholds to define reports of severe weather events, naturally including the seven which do not collect non-severe events.

The reporting parameters vary widely from one country to the next. Seventeen of 19 NMHSs (89\%) receive informa- 


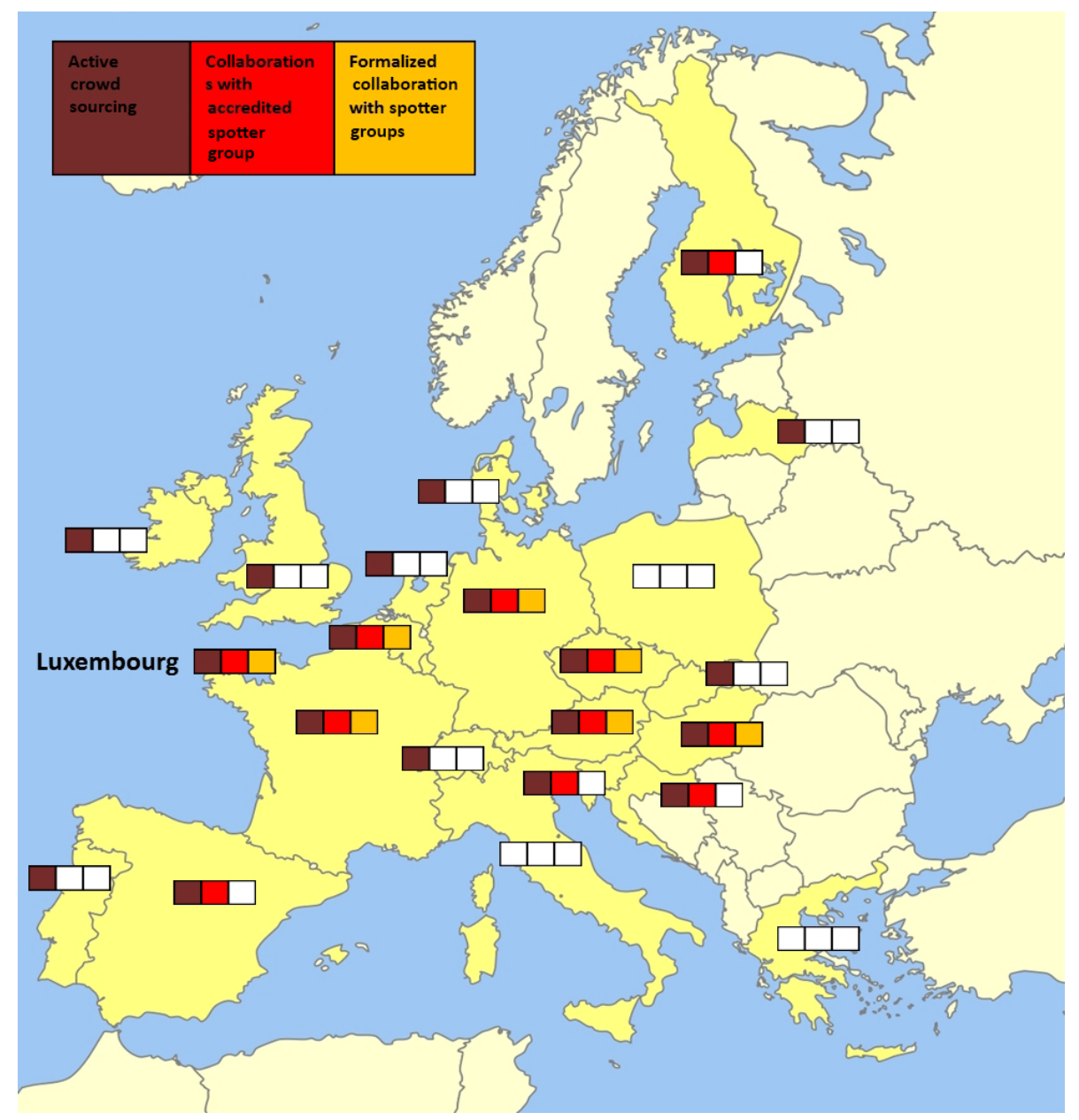

Figure 2. Results from our survey by countries, Part 1: crowdsourcing and collaborations between NMHSs and spotter groups.

tion about multiple reporting parameters. Hail, strong wind, heavy rain, lightning activity, or snowfall (wintry road conditions) was most frequently listed in our survey. In two cases, only one parameter is processed, namely hail size in Switzerland and snow depth in Denmark. Four NMHSs (21\%) receive also hydrological event types like river flooding, and two NMHSs $(11 \%)$ geological event types (e.g., rock- or landslides) or maritime event types (e.g., waterspouts or tidal flooding), respectively.

Table 1 summarizes the different ways how crowdsourced information is transferred to the NMHSs (Question C.2). Reporting forms (including apps) are the most common way, followed by social media channels, telephone hotlines and email. Interestingly, amateur radio ("ham radio") was mentioned not a single time, though it is frequently used in the USA for communication between storm spotters, emergency units and the National Weather service.
Table 1. Means of information transfer from spotter organizations to NMHSs. Multiple selections were possible.

\begin{tabular}{lr}
\hline Reporting forms and apps & $89 \%$ \\
Social media & $58 \%$ \\
Telephone & $47 \%$ \\
Email & $37 \%$ \\
Private weather stations & $32 \%$ \\
Short message service (phone) & $10 \%$ \\
Amateur radio & $0 \%$ \\
\hline
\end{tabular}

\section{Discussion and conclusions}

European NMHSs are recently increasing their efforts towards issuing impact-based weather forecasts and warnings. However, automated station networks alone are not able to provide the necessary observational database for these purposes. The decreasing number of official weather observers among the services intensifies the lack of observational data, especially with respect to a weather phenomenon's impact 


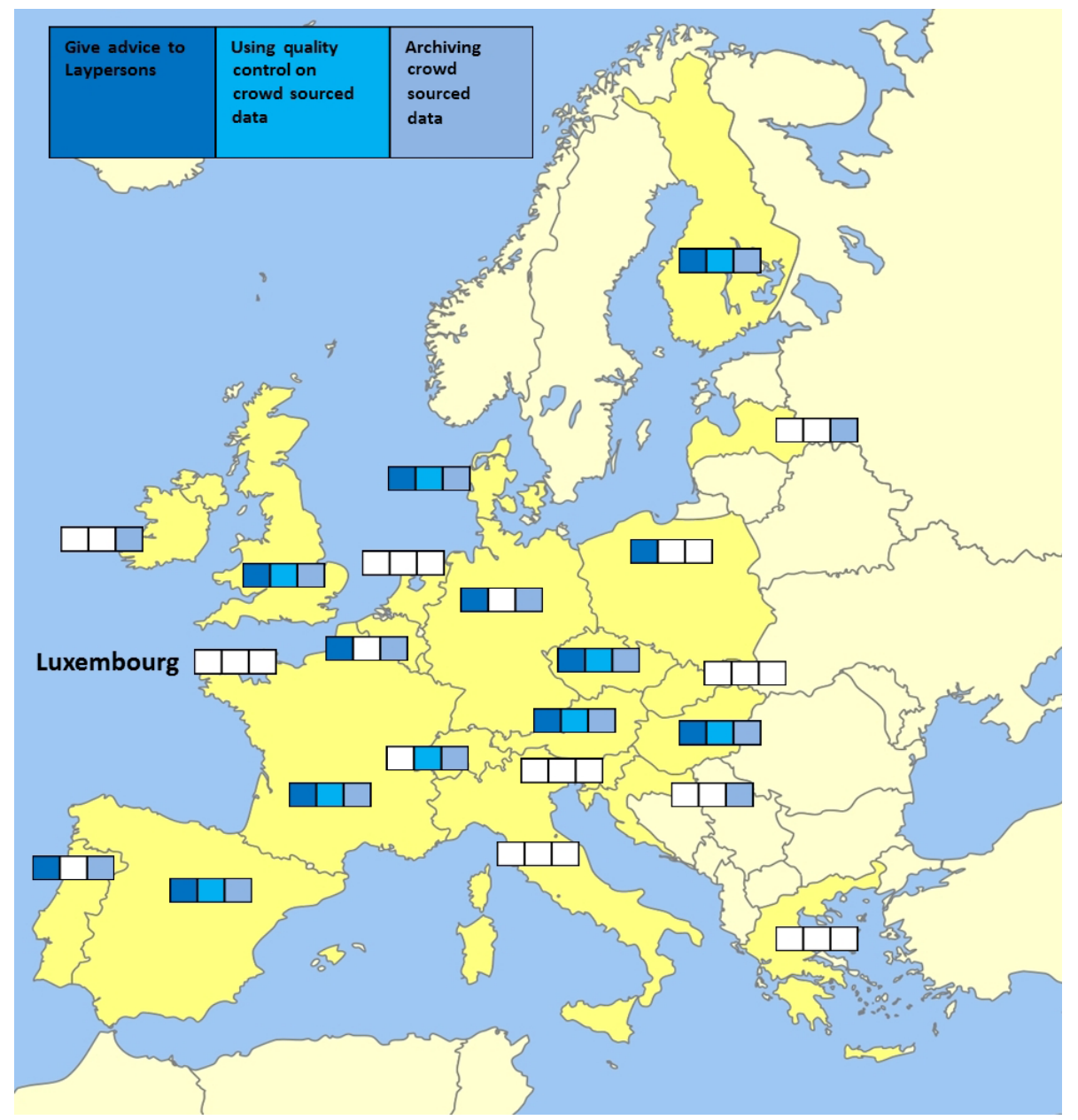

Figure 3. Results from our survey by countries, Part 2: quality management and archiving of reports.

on the ground. As an alternative, NMHSs collaborate more frequently with voluntary observers, weather enthusiasts or organized spotter groups. Our study showed an increase in the deployment of such collaborations from less than $20 \%$ of surveyed countries in 2007, as found by Rauhala and Schultz (2009), to $58 \%$ in 2017. Including crowdsourcing activities without official collaboration between NMHSs and storm spotter organizations raises this number to even $86 \%$.

NMHSs which participated in our survey were requested to give additional information how the crowdsourced information is used (Question C.3). These answers were too informal to allow us an unambiguous categorization, but the main areas of use can be summarized as follows, qualitatively ranked with respect to the number and prominence of nominations:

- an improvement of weather forecasts and warnings in real-time;

- verification of weather warnings;
- the establishment of a climatology of severe or unusual weather events;

- case studies or damage reports;

- inclusion of private weather station data into the data assimilation of numerical weather prediction models; and

- a strengthening of the relationship between NMHSs and their country's citizens.

Our survey showed that, formally or informally, nearly all forecasters from European NMHSs search for additional, non-conventional information about weather events and their impact. The ever-increasing facilitation of transmitting information, also including large data quantities like pictures and videos, in real-time fosters an evidently rising importance of human ground impact observations.

A substantial number of European NMHSs takes their outreach to spotter groups seriously enough to formalize their collaborations and to provide advice, education and training in return for the received spotter reports. However, another interesting aspect is that only one of the surveyed 
NMHSs - the Zentralanstalt für Meteorologie und Geodynamik (ZAMG) in Austria - links training of storm spotters to quality control of their reports. Doing so allows an automatic assignment of higher quality flags to reports of trained storm spotters, which enables a quicker procession by the forecaster on duty and an increase in lead times of severe weather warnings, which are often critically low, especially with respect to tornadoes (Doswell III et al., 1999; Rauhala and Schultz, 2009). A need for spotter trainings to increase the usefulness of their reports was recognized long ago in the United States of America, and such training programs were already established in the 1950s (Doswell III et al., 1999). The inertia in exploiting such mutually beneficial aspects of collaborations between NMHSs and spotter organizations in Europe is therefore somewhat surprising. We think that the Austrian way could act as a role model for other European countries and present it in a follow-up paper of this issue (Krennert et al., 2018). A further rapid development of crowdsourcing activities in connection with weather and damage observations in Europe is to be expected, and linking training and quality management will enable an even more efficient real-time use of these data.

Data availability. We declare, that for the composition of this article we used our own dataset resulting from the survey of European NMHSs about their crowdsourcing activities. No datasets from other resources have been used.

Competing interests. The authors declare that they have no conflict of interest.

Special issue statement. This article is part of the special issue "17th EMS Annual Meeting: European Conference for Applied Meteorology and Climatology 2017'. It is a result of the EMS Annual Meeting: European Conference for Applied Meteorology and Climatology 2017, Dublin, Ireland, 4-8 September 2017.

Edited by: Haleh Kootval

Reviewed by: David Rogers and one anonymous referee

\section{References}

Bonney, R., Cooper, C. B., Dickinson, J., Kelling, S., Phillips, T., Rosenberg, K. V.. and Shirk, J.: Citizen science: a developing tool for expanding science knowledge and scientific literacy, BioScience, 59, 977-984, https://doi.org/10.1525/bio.2009.59.11.9, 2009.

Doswell III, C. A., Moller, A. R., and Brooks, H. E.: Storm spotting and public awareness since the first tornado forecasts of 1948, Weather Forecast., 14, 544-557, https://doi.org/10.1175/15200434(1999)014<0544:SSAPAS>2.0.CO;2, 1999.

Eitzel, M. V., Cappadonna, J. L., Santos-Lang, C., Duerr, R. E., Virapongse, A., West, S. E., Kyba, C. C. M., Bowser, A., Cooper, C. B., Sforzi, A., Metcalfe, A. N., Harris, E. S., Thiel, M., Haklay, M., Ponciano, L., Roche, J., Ceccaroni, L., Shilling, F. M., Dörler, D., Heigl, F., Kiessling, T., Davis, B. Y., and Jiang, Q.: Citizen Science Terminology Matters: Exploring Key Terms, Citizen Science: Theory and Practice, 2, 1-20, https://doi.org/10.5334/cstp.96, 2017.

Estellés-Arolas, E. and González-Ladrón-de-Guevara, F.: Towards an Integrated Crowdsourcing Definition, J. Inform. Sci., 38, 189200, https://doi.org/10.1177/0165551512437638, 2012.

Krennert, T., Kaltenberger, R., Pistotnik, G., Holzer, A. M., Zeiler, F., and Stampfl, M.: Trusted Spotter Network Austria - a new standard to utilize crowdsourced weather and impact observations, Adv. Sci. Res., 15, 77-80, https://doi.org/10.5194/asr-1577-2018, 2018.

Rauhala, J. and Schultz, D. M.: Severe thunderstorm and tornado warnings in Europe, Atmos. Res., 93, 369-380, https://doi.org/10.1016/j.atmosres.2008.09.026, 2009.

Shirk, J. L., Ballard, H. L., Wilderman, C. C., Phillips, T., Wiggins, A., Jordan, R., McCallie, E., Minarchek, M., Lewenstein, B. V., Krasny, M. E., and Bonney, R.: Public participation in scientific research: a framework for deliberate design, Ecol. Soc., 17, 29, https://doi.org/10.5751/ES-04705-170229, 2012. 